\title{
O que é o Real? A busca inconclusa sobre o significado da física quântica
}

What is Real? The unfinished quest for the meaning of quantum physics

\author{
Gustavo Rodrigues Rocha*1] \\ ${ }^{1}$ Universidade Estadual de Feira de Santana, Novo Horizonte, BA, Brasil
}

Recebido em 14 de Abril, 2018. Revisado em 19 de Julho, 2018. Aceito em 07 de Agosto, 2018

A. Becker, What is Real? The unfinished quest for the meaning of quantum physics (Basic Books, New York, 2018)

O filme Quem Somos Nós? (What the Bleep do We Know?, em sua versão original em inglês), de 2004, que ganhou uma versão estendida em 2006, de título What the Bleep!?: Down the Rabbit Hole, atraiu uma série de críticas severas, vindas de cientistas, jornalistas e educadores de ciências, publicadas em jornais, livros e revistas de divulgação científica. A Physics Today, por exemplo, devido ao sucesso do filme, publicou, em sua edição de novembro de 2006, uma carta, Teaching Physics Mysteries Versus Pseudoscience[1], onde os autores afirmam que "um estudante de física é incapaz de confrontar convincentemente as extrapolações injustificadas a respeito da mecânica quântica, contrariamente a um estudante de biologia que é capaz de defender a evolução contra o 'Desígnio Inteligente".

Para os autores, Fred Kuttner, professor de física da Universidade da Califórnia em Santa Cruz, e Bruce Rosenblum (ex-professor da mesma universidade já falecido), a culpa não é dos estudantes, mas do modo como a mecânica quântica é ensinada hoje, o qual nega, tacitamente, os mistérios envolvidos em sua interpretação.

Portanto, a importância de se introduzir boas referências a respeito das interpretações da mecânica quântica na formação de professores do ensino médio e universitário, assim como na divulgação científica e na formação de cientistas, parece inegável e urgente.

É nesse contexto que se destaca o livro de Adam Becker, What is Real? The unfinished quest for the meaning of quantum physics, de 2018, uma história dos debates em torno das interpretações da teoria quântica que, ademais, publicado pela editora comercial Basic Books, e fomentado pela Alfred P. Sloan Foundation (através de seu programa dirigido à divulgação científica), também é voltado para o público leigo.

De fato, Becker reúne duas qualidades, de escritor de divulgação científica, tendo escrito para a $B B C$ e para a New Scientist, e de historiador da ciência, atualmente associado, como pesquisador visitante, ao Office for History of Science and Technology da Universidade da Califór-

*Endereço de correspondência: gustavo.rodrigues.rocha@gmail.com nia em Berkeley (obteve o seu doutorado em cosmologia pela Universidade de Michigan e graduou-se em física e filosofia pela Universidade de Cornell). Não por acaso, a leitura de What is Real?, obra dividida em três partes, cada qual composta de quatro capítulos, é agradável e palatável para diversos públicos, prende a atenção do leitor do início ao fim, sem deixar a desejar em rigor histórico e filosófico.

Becker não deixa, contudo, ao delinear essa fascinante história, de se posicionar em relação às sua preferências filosóficas, tendo como fio condutor de sua narrativa a sua insatisfação com a interpretação de Copenhague, o que já se torna evidente no título da primeira parte do livro, "uma filosofia calmante" (tradução livre do original "a tranquilizing philosophy"), uma referência a Albert Einstein que assim chamou a interpretação de Copenhague em uma carta a um amigo.

Dos capítulos 1 ao 4, primeira parte do livro, o autor de What is Real? traça os caminhos que levaram ao nascimento da mecânica quântica (incluindo as suas primeiras formulações na mecânica matricial de Heisenberg e na mecânica ondulatória de Schrödinger) e à dominância da interpretação de Copenhague (incluindo como razões desse predomínio a áurea de sábio de Niels Bohr, a famosa prova de von Neumann, cuja autoridade como gênio matemático ajudou a manter a interpretação de Copenhague inquestionável, o clima da cultura da República Alemã de Weimar e a hegemonia da filosofia positivista).

$\mathrm{O}$ autor também apresenta nessa primeira parte como transcorreram os debates entre os insatisfeitos com a mecânica quântica e a interpretação de Copenhague e os seus defensores (incluindo as interpretações alternativas de Schrödinger e Louis De Broglie e os famosos debates nas conferências de Solvay de 1927 e 1930 entre o insatisfeito Einstein e o principal proponente da interpretação de Copenhague Niels Bohr). Becker apresenta também o principal argumento e inquietude de Einstein, que constituía na violação do princípio da localidade, o que culminou, ao fim e ao cabo, no seu famoso artigo EPR (Einstein-Podolsky-Rosen) de 1935. 
No quarto e último capítulo da primeira parte, Becker explica e delineia como que os calorosos debates em torno das interpretações da recém-nascida teoria quântica se dissiparam a partir do pós-Guerra. O clima que se estabeleceu (que se tornaria conhecido como a filosofia do "shut up and calculate!", expressão atribuída ao filósofo da mecânica quântica David Mermin) favoreceu ainda mais a dimensão positivista (na opinião de Becker) da interpretação de Copenhague (que também é entendida, por outros autores, através de diferentes tradições filosóficas, como o pragmatismo ou o neokantismo). De todo modo, a pesquisa em fundamentos da mecânica quântica se tornou proibitiva em sala de aula e os livros textos evitavam questões de interpretações da mecânica quântica.

A demanda por mão de obra especializada nos EUA durante a Guerra Fria produziu um crescimento exponencial de físicos teóricos e experimentais a partir da década de 1950 até meados da década de 1970, sendo que $98 \%$ do orçamento para pesquisa básica em ciências físicas nos EUA advinham de agências governamentais orientadas pelo complexo industrial militar e de defesa. O modus operandi da física teórica mudou devido a esse contexto. Os revisores de revistas de física teórica eram orientados a rejeitarem "discussões filosóficas", como documentado por Becker e KAISER, D.; 2011[2].

Dos capítulos 5 a 8, segunda parte do livro, intitulada "dissidentes quânticos" ("quantum dissidents"), uma menção ao trabalho de FREIRE JR., O.; 2015[3], Becker discorre sobre os principais autores que ousaram quebrar o silêncio do "shut up and calculate!" que favorecia a interpretação de Copenhague propondo interpretações alternativas. No capítulo 5, Becker delineia a trajetória de David Bohm que propôs em seus artigos de 1952 a interpretação da onda-piloto, uma versão de teoria de variáveis ocultas que, em certa medida, é um retorno à ideia de De Broglie de 1927.

No capítulo 6, o autor de What is Real? traça o caminho que levou Hugh Everett à chamada interpretação dos muitos mundos a partir de sua tese de doutorado defendida em 1957 sob a orientação de John Wheeler em Princeton. Wheeler mandou a tese de Everett para Schrödinger, Oppenheimer e Eugene Wigner (que não responderam ou não se impressionaram). Niels Bohr não gostou. Bryce DeWitt, que trabalhava em cosmologia quântica, colega de Wheeler, tornou-se um dos primeiros adeptos da interpretação dos muitos mundos de Everett.

No capítulo 7, Becker disserta sobre a trilha tomada por John Bell que, baseado em uma versão de David Bohm do argumento apresentado no artigo EPR (EinsteinPodolsky-Rosen) (o chamado paradoxo EPR), chegou ao famoso "teorema de Bell" (também conhecido como "desigualdades de Bell") em trabalho publicado em 1964. John Bell sugeriu uma maneira possível de colocar a teoria quântica como um todo sob o escrutínio de uma investigação experimental.

O capítulo 8 é dedicado a descrever a ascensão e o declínio do positivismo lógico (ou neopositivismo). Becker mostra como os criadores da mecânica quântica e os positivistas partilhavam do mesmo Zeitgeist, tendo o próprio Niels Bohr hospedado um dos congressos dos positivistas em sua residência em Copenhague em 1939.

Na década de 1960, a chamada filosofia pós-positivista da ciência (através de nomes como Hilary Putnam, Karl Popper, Norwood Russell Hanson, W. V. O. Quine, P. Feyerabend e T. Kuhn) questionou a hegemonia do positivismo.

O argumento de Becker é que uma importante base filosófica de sustentação da interpretação de Copenhague estava em declínio por volta da mesma época em que os "dissidentes quânticos" questionavam a interpretação de Copenhague - o que, de certo modo, contribuiu para a recuperação da pesquisa em fundamentos da mecânica quântica.

Dos capítulos 9 a 12, terceira e última parte do livro, intitulada "a grande empreitada" (tradução livre do original "the great enterprise"), Becker discorre sobre o renascimento da pesquisa acadêmica em fundamentos da mecânica quântica, a começar pelo momento quando o teorema de Bell é finalmente testado em laboratório.

O capítulo 9 trata do encontro de John Clauser com o trabalho de Bell e de sua colaboração com A. Shimony, M. Horne e R. Holt, que resultou no artigo Clauser-HorneShimony-Holt, que delineou como seria um experimento para testar as desigualdades de Bell. Com efeito, trabalhando com o seu assistente S. Freedman, Clauser conduziu esse experimento na Universidade de Berkeley, Califórnia, publicando os seus resultados em 1972 (sucesso que seria replicado com maior precisão por físicos como Alain Aspect em 1982).

Paralelamente, o autor conta os percalços do físico alemão Heinz-Dieter Zeh que, insatisfeito com a mecânica quântica, e a despeito dos conselhos do seu orientador, Hans Jensen, para não se envolver com pesquisa sobre os fundamentos da mecânica quântica, acabou por oferecer um solução original ao chamado "problema da medição" em seu programa de pesquisa conhecido como decoerência quântica a partir do seu seminal artigo de 1970.

A política supracitada de periódicos rejeitarem artigos em fundamentos da mecânica quântica não apenas relaxou a partir desse período como novos periódicos surgiram e se destacaram por cumprirem esse papel, como a Foundations of Physics e as Epistemological Letters.

A Escola de Verão de Varena na Itália em 1970 ficou conhecida como a "Woodstock dos dissidentes quânticos" reunindo nomes como H. D. Zeh, David Bohm, Bryce DeWitt, Louis De Broglie, Eugene Wigner, Abner Shimony e John Bell. Em Berkeley, formou-se o excêntrico Fundamental Fysiks Group[2].

No capítulo 10, curiosamente intitulado "primavera quântica" ("quantum spring"), o autor de What is Real? esboça como no período recente a pesquisa em fundamentos de mecânica quântica atingiu o mainstream, principalmente a partir das promessas da informação e da computação quântica, o que levou, pouco a pouco, a inici- 
ativa privada e os governos dos EUA, dos países da União Europeia e da China a investirem bilhões de dólares por ano nessas pesquisas.

No capítulo 11, o autor mostra como as diversas interpretações diferentes de Copenhague se popularizaram e se entremearam com outras áreas de pesquisa, como computação e cosmologia, assim como conquistaram novos ilustres adeptos. Finalmente, no capítulo 12, Becker retira conclusões gerais e discorre um pouco sobre novos personagens que fizeram bem-sucedidas carreiras em fundamentos da mecânica quântica, como David Albert e Anton Zeilinger.

Os pontos frágeis do livro são: Em primeiro lugar, a concepção de uma suposta (e somente uma) bem delineada interpretação de Copenhague. O próprio autor admite que tal unidade nunca existiu. Todavia, ainda assim, Becker se utiliza, como pano de fundo de sua narrativa, de um espantalho (ou caricatura, a saber, a sua própria versão da interpretação de Copenhague) contra o qual constrói os seus argumentos.

A interpretação de Copenhague - a grande vilã da narrativa de Adam Becker - cuja apresentação de seu formalismo matemático na obra de 1932 de von Neumann estimulou as interpretações subjetivistas (como de início as interpretações de Fritz London e Edmond Bauer e Eugene Wigner) - é a culpada (para o autor) inclusive pelas confusões que levariam a filmes como Quem Somos Nós? (mencionado no início dessa resenha) e O Segredo (que o autor chama de "New Age nonsense and junk pseudo-science").

Em segundo lugar, a sua narrativa não é exaustiva, ignorando uma série de conferências, periódicos científicos e autores que, dentro do mesmo período histórico escolhido, contribuíram para o renascimento da pesquisa em fundamentos da mecânica quântica.

Os pontos positivos, todavia, são evidentes e encantam o leitor: a riqueza de material empírico, pesquisa em arquivos e entrevistas, e o uso da extensa literatura secundária, além de artigos e livros de fontes primárias. O livro é fruto de muita pesquisa e se destaca como uma contribuição inquestionável para a literatura. Becker realizou mais de quarenta entrevistas para escrever o seu trabalho (incluindo os principais nomes importantes na história dos fundamentos da mecânica quântica).

O livro é altamente indicado para educadores e professores de física, filósofos, estudantes, historiadores e interessados nos mistérios da mecânica quântica. A leitura é acessível e pode ser indicada e utilizada em todos os níveis de maior ou menor aprofundamento, da divulgação científica à formação de professores.

\section{Referências}

[1] F. Kuttner e B. Rosenblum, Physics Today 59, 14 (2006).

[2] D. Kaiser, How the Hippies Saved Physics: Science, Counterculture, and the Quantum Revival (W. W. Norton \& Company, New York, 2011).
[3] O. Freire Jr., The Quantum Dissidents: Rebuilding the Foundations of Quantum Mechanics (1950-1990) (Springer-Verlag, Berlin, 2015). 